ISSN: 2238-8052

\title{
A VIOLÊNCIA NO BAIRRO NOSSA SENHORA DA APRESENTAÇÃO EM NATAL/RN: UMA ANÁLISE DA CONSTITUIÇÃO DO TERRITÓRIO DA VIOLÊNCIA EM AMBIENTE DE MEDO
}

\author{
VIOLENCE IN NOSSA SENHORA DA APRESENTAÇÃO NEIGHBOURHOOD/RN: AN ANALYSIS OF \\ THE CONSTITUTION OF VIOLENCE IN AN ENVIRONMENT OF FEAR
}

\author{
Emilly Domingos da SILVA ${ }^{1}$ \\ Maria Cecília Cordeiro de BRITO² \\ Hugo Arruda de MORAIS ${ }^{3}$
}

Artigo recebido em 10/05/2019 e aceito em 11/07/2019

Palavras-chave:

Espaço urbano,

Bairr,

Territorialização,

Ambiente de medo.
Keywords:

Urban space,

Neighborhood,

Territorializatio,

Fear environment.

\section{R E S U M O}

Este artigo propõe reflexões acerca da violência, do medo e da pobreza enquanto fenômenos articulados que fazem parte do território urbano hodierno. A partir deste quadro de referências, foi possível verificar que a desigualdade socioterritorial constitui a principal causa, também nos grandes centros urbanos, do crescimento da violência em ambiente de medo. Partindo de uma análise territorial, espacializa-se esses fenômenos a fim de observar a dimensão da influência e dos impactos provocados pela disseminação cada vez mais notável da violência "urbana" e, consequentemente, de um medo que já se acha instaurado em nossa sociedade, mas que diante de um cenário citadino caótico, torna-se ainda mais proeminente. Nessa perspectiva, o obejtivo central do artigo é compreender, a partir da análise de dados socioespaciais para Natal/RN, em que medida Nossa Senhora da Apresentação se caracteriza como um território da violência e do medo. Nesse sentido, o texto foi subdividido em três seções: no primeiro momento, discutir-se-á a espacialização da pobreza em grandes cidades no Brasil, levando em consideração os aspectos sociais, sua disposição e consequências no território citadino. No segundo momento, será analisado o conceito de território e suas ramificações, levando em conta os fenômenos do medo e da violência. E, por fim, será analisado o bairro Nossa Senhora da Apresentação, no município de Natal-RN, a fim de apreender a territorialização da violência e seus agentes.

\section{A B S T R A C T}

This article proposes reflections with regard to violence, fear and poverty as articulated phenomena that take part of today's urban territory. From this context, it was possible to verify that socio-territorial inequality is the main cause, also in the great urban centers, of the growth of violence in fear environment. Starting from a territorial analysis, these phenomena are spatialized in order to observe the dimension of influence and the impacts caused by the increasingly notable dissemination of "urban" violence and, consequently, of a fear that is already established in our society, but before a chaotic city scene, it becomes even more prominent. From this perspective, the central objective of the article is to understand, from the analysis of socio-spatial data for Natal/RN, to what extent Nossa Senhora da Apresentação is characterized as a territory of violence in the currently fear environment. In this sense, the text was subdivided into three sections: firstly, we will discuss the spatialisation of poverty in large cities in Brazil, taking into account the social aspects, their disposition and consequences in the city. In the second

\footnotetext{
1 Graduanda em Geografia da Universidade Federal do Rio Grande do Norte. E-mail: cecilia_britto@outlook.com. 2 Graduanda em Geografia da Universidade Federal do Rio Grande do Norte. E-mail: emillydoomingos@gmail.com. 3 Professor Adjunto do Departamento de Geografia da Universidade Federal do Rio Grande do Norte. Vice-Líder do grupo de pesquisa Movimentos Sociais e Espaço Urbano. E-mail: hugo.geografia@yahoo.com.br.
} 
moment, the concept of territory and its ramifications will be analyzed, taking into account the phenomena of fear and violence. Finally, we will analyze the neighborhood Nossa Senhora da Apresentação, in Natal, in order to apprehend the territorialization of violence and its agents.

\section{INTRODUÇÃO}

Um olhar holístico é primordial para compreender as relações que se dão no espaço geográfico, principalmente para identificar as vinculações socioespaciais que se instauram e estruturam a vida do ser humano no seu território. Se levarmos em consideração que tais fatos se dão dialeticamente, “(...) o espaço é mais do que um simples receptáculo das ações humanas, pois os fenômenos não apenas sobre ele ocorrem, mas também são por ele produzidos" (SANTOS, 1999, p. 61).

O espaço está marcado pelo crescimento desenfreado dos grandes polos urbanos, cujo processo de expansão sem um planejamento e estruturação consequentes corroboram para que alguns desses polos se organizem por meio de processos disformes que potencializam as desigualdades existentes. Esse fenômeno cria e recria os centros urbanos fazendo com que eles carreguem em sua essência a fragmentação do espaço.

No Brasil e no mundo, as grandes cidades têm sido o ambiente no qual diferentes tipos de violência assolam a sociedade que busca desesperadamente novas estratégias para se resguardar. É notável que na última década tenha ocorrido um aumento exponencial da violência nos grandes centros urbanos, propagando um ambiente de medo que nunca se tinha visto antes.

Tal escalada pode ser comprovada pelo aumento gradual dos índices que ratificam o fenômeno, mas também pela sensação de insegurança que se instaura no cotidiano da população que busca cada vez mais meios de se prevenir, seja pela busca de aparatos tecnológicos (câmeras, cercas elétricas, vigilantes, etc.) ou pela mudança de hábitos (como a alternância nas rotas habituais para evitar a passagem por locais susceptíveis ao perigo).

A cidade de Natal, situada no Estado do Rio Grande do Norte, não está alheia a este fenômeno que se faz cada vez mais comum nos grandes centros urbanos quando o assunto é a escalada da violência, apresentando bairros onde há significativa concentração de Crimes de Violência Letal Intencional (CVLI). Desta forma, este estudo busca compreender e delimitar o fenômeno ora em apreço tendo como campo de análise o bairro Nossa Senhora da Apresentação, que se localiza na Zona Administrativa Norte da capital, o qual detém a designação de bairro mais violento da cidade, de acordo com os dados levantados. Busca-se, assim, compreender, a partir, também, da análise de dados socioespaciais de Natal/RN, em que medida Nossa Senhora da Apresentação se caracteriza como um território da violência e do medo.

No que diz respeito à metodologia empregada nesta pesquisa, foi efetuado um levantamento bibliográfico que contribuiu para estruturação de ideias que nortearam nossa discussão. Na busca de 
uma base representacional do fenômeno ora abordado, utilizou-se técnicas de geoprocessamento para fazer o mapeamento do fenômeno (contorno do bairro, loteamentos e espacialização dos CVLI nos bairros de Natal) através da coleta de dados. Para a produção dos mapas, utilizou-se a ferramenta ArcMap 10.6.1 contando com dados do IBGE e do Google Earth, de modo que a sistematização das ideias com o auxílio dos dados apresentados foi essencial para se obter uma grande quantidade de informações sobre o local e conseguir espacializar o fenômeno da violência e do medo. Também nos utilizamos de dados do Observatório da Violência Letal Intencional no Rio Grande do Norte (OBVIO), dispostos em boletins periódicos. Como os relatórios do OBVIO dispõem de uma ampla gama de dados, tendo em vista que a análise de todas as informações se mostrou inviável para este trabalho, resolveuse debruçar sobre a ocorrência específica de violência representada pelos Crimes de Violência Letal Intencional (CVLI). A partir da análise quantitativa dos dados foi possível estabelecer parâmetros realçando os locais com mais incidência.

0 trabalho encontra-se subdividido em três seções. No primeiro momento, discutir-se-á a espacialização da pobreza em grandes cidades no Brasil, levando em consideração os aspectos sociais, sua disposição e consequências no território citadino. No segundo momento, analisar-se-á o conceito de território e suas ramificações, levando em conta os fenômenos do medo e da violência. E, por fim, discutir-se-á a situação do bairro Nossa Senhora da Apresentação a fim de apreender a natureza da violência e seus agentes no processo de sua territorialização.

\section{ESPACIALIZAÇÃO DA POBREZA EM GRANDES CIDADES NO BRASIL}

Falar sobre pobreza no Brasil é algo extremamente complexo, já que o país tem dimensão continental e, consequentemente, o fenômeno especializa-se de maneiras diferentes nos múltiplos territórios do país. A pobreza não está restrita aos países do sul, pois na contemporaneidade esse fenômeno se espraia por todos os territórios, também nos países do norte, que compões os grandes centros urbanos, suas periferias e seus campos. A pobreza está contida nos elementos materiais e imateriais possuindo suas raízes na formação histórico-territorial da sociedade brasileira.

Segundo o Banco Mundial (2000), a pobreza tem como principais características, formando uma tríade: a) a falta de recursos e renda para atender às necessidades básicas como saúde, educação, alimentação, deslocamento; b) a falta de voz e poder nas instituições e na sociedade; e, por fim, c) a vulnerabilidade frente a riscos, combinados com a impossibilidade de enfrentá-los. Estas características ainda se tornam muito mais grave em países como o Brasil, na medida em que sua formação territorial aconteceu no âmbito de uma forte divisão de classes.

Sendo assim, pode-se dizer que a pobreza é a privação ou a ausência de atendimento às necessidades humanas básicas como abrigo, comida, vestuário, educação, assistência à saúde e mobilidade, entre outros. No Brasil, tal fenômeno pode ser observado principalmente nos grandes 
centros urbanos, especialmente nas suas periferias. A formação de favelas nas áreas periféricas ou inadequadas da cidade é resultado da deficiência habitacional existente em todo o país. Quanto a isso, Corrêa (1989) diz que:

É na produção da favela, em terrenos públicos ou privados invadidos, que os grupos sociais excluídos tornam-se, efetivamente, agentes modeladores, produzindo seu próprio espaço (...). A produção deste espaço é, antes de mais nada, uma forma de resistência e, ao mesmo tempo, uma estratégia de sobrevivência" (CORRÊA, 1989, p. $30)$.

Partindo desses preceitos, nota-se a fragmentação do espaço geográfico, a qual gera características discrepantes, ou seja, espaços elitizados, com maior inserção do capital, serviços e direitos, bem como a presença do Estado, além de condições para uma mobilidade estratégica nestes territórios; e espaços pobres, com falta de investimentos provenientes do Estado e carências assistenciais básicas, engendrando formas de ocupação irregulares, o que limita o exercício da cidadania. Segundo Barros, Henrique e Mendonça (2000, p. 3), “(...) o Brasil não é um país pobre, mas um país com muitos pobres; no Brasil não falta recursos, estes é que são mal distribuídos e se concentram muito nas mãos de uns, enquanto a maioria detém o mínimo". Para se obter uma compreensão sobre tal organização socioespacial é necessária uma análise histórica que constate como ocorreu o processo de ocupação desse espaço e, principalmente, por quem.

As periferias são áreas deixados à margem da sociedade. Na tentativa de frear esse processo, existem inúmeros atores que buscam amplificar a voz dos "indesejáveis", moradores da periferia, que por meio da arte (música, dança, poesia, grafite) conseguem transmitir para o mundo os anseios e as dificuldades que trazem tatuados em si e revelam a verdadeira face da periferia. Como equalizadores dessa mensagem podemos citar Emicida, Rachide, Iza, Karol Conka, Racionais MC, que trazem através de sua música a exposição da perversa realidade enfrentada no cotidiano dos indivíduos que vivem nesses conglomerados. E, como exemplo, pode-se citar a música "Fim de Semana no Parque" do grupo Racionais Mc's que diz:

\section{[...]}

Olha só aquele clube que da hora.

Olha aquela quadra, olha aquele campo, olha

Olha quanta gente

Tem sorveteria, cinema, piscina quente

Olha quanto boy, olha quanta mina

[...]

Tem corrida de kart dá pra ver

É igualzinho o que eu vi ontem na TV

Olha só aquele clube que da hora,

Olha o pretinho vendo tudo do lado de fora

Nem se lembra do dinheiro que tem que levar

Do seu pai bem louco gritando dentro do bar

Nem se lembra de ontem, de hoje e o futuro

Ele apenas sonha através do muro 


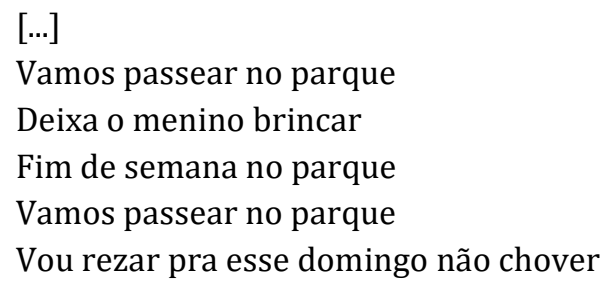

A música retrata um bairro da zona Sul de São Paulo, um local de "rico", as precárias condições de vida tornam-se um dos traços expressivos do cenário urbano brasileiro. Pode-se perceber a discrepância presente na materialidade dos bairros elitizados através da descrição que o grupo faz na música, bem como o fato de que para os moradores da periferia metropolitana usufruírem dos mesmos serviços, eles precisam se deslocar até àqueles polos. De acordo com Sen (1999, p. 6), “(...) a pobreza pode ser definida como uma privação das capacidades básicas de um indivíduo", o que por sua vez demonstra a estratificação da cidade, que pode ser observada pela falta de infraestrutura e serviços básicos, acarretando ruptura social dos moradores das periferias, pois os mesmos não conseguem exercer o direito à cidade muitas vezes simplesmente pela dificuldade de se ter acessibilidade dentro da própria cidade em que vive.

Isso claramente acentua a espacialização da pobreza, visto que não somente os serviços básicos, mas tudo o que está disposto na esfera citadina, são monopolizados por aqueles que detêm o capital. 0 que realça a perversidade do sistema capitalista, que permeia uma cortina de interesses e necessidades econômicas que configuram um espaço diferenciado entre os que podem se apropriar e os que não têm acesso total ao mesmo, constituindo parcelas espaciais homogêneas e fragmentadas. Nesse sentido, Silva (2010) coloca: “É, porém, o paradigma de inspiração liberal, nas suas diferentes variações, o mais recorrente nas explicações e nas orientações de políticas públicas na sociedade capitalista" (SILVA, 2010, p. 157).

Nesse contexto, o capitalismo tem um papel fundamental na espacialização da pobreza e na valorização dos espaços ocupados por elites, favorecendo os mesmos e, por consequência, há a manutenção do sistema de privilégios, onde o proletariado sofre com a falta de acesso a direitos básicos e de políticas públicas, já que estas são, historicamente, direcionadas a um grupo seleto.

A ansiedade e o medo se dão como consequências do sentimento de incerteza e impotência, ou seja, o homem é cheio de expectativas e, ao se deparar com a realidade que lhe é imposta como uma barreira de segregação, não detendo o poder de alcançar seus objetivos de forma que seu corpo seja afetado, isso faz com que o mesmo reaja hostil e violentamente. E quanto mais impotente esse corpo for, maior será a intensidade da violência que ele demonstrará.

$\mathrm{Na}$ atual conjuntura espacial, os veículos de comunicação e os poderes estatais corroboram com a disseminação do discurso segundo o qual os bairros periféricos são extremamente violentos. Isso não significa que os pobres sejam mais violentos, mas demonstra que a impotência à qual são 
expostos os encurrala de tal forma que, em determinados momentos, só atos violentos ${ }^{4}$ mostram-se como alternativas para a redenção e sobrevivência.

A violência comumente se associa à pobreza, a não ausência do Estado ${ }^{5}$, à segregação de espaços e ao próprio processo de urbanização regido pela perversidade do capital, que cria e recria as periferias. Os temas violência e medo se tornam extremamente complexos e de grande abrangência, tendo em vista que não é possível criar um mapa do crime, pois tal fenômeno é líquido e se espraia de forma não homogênea no território criando, assim, bolsões onde a violência e o medo se difundem e exercem influência sobre o espaço.

Ressalta-se que é no território que ocorre a junção desses fenômenos que se articulam, se totalizam e se contradizem, fazendo-se necessário compreender a violência e a sua dinâmica, bem como a maneira através da qual ocorrem os processos de sua territorialização e desterritorialização e, consequentemente, do medo.

\section{TERRITÓRIO E TERRITORIALIZAÇÃO DA VIOLÊNCIA EM AMBIENTE DE MEDO}

É de fundamental importância compreender o conceito de território e suas variantes, já que o bairro Nossa Senhora da Apresentação dispõe de uma tênue relação entre território e violência, pois os vazios de poder deixados pelo Estado corroboram para a territorialização de agentes do crime que vêm deixando os moradores que vivem nesses aglomerados mais susceptíveis à violência em um ambiente em que o medo do crime faz-se cada vez maior.

Como amparo desta discussão acerca do território, considera-se a perspectiva segundo a qual tratar da sociedade requer levar em conta sua territorialização; assim, "não há como definir o indivíduo, o grupo, a comunidade, a sociedade sem ao mesmo tempo inseri-los num determinado contexto geográfico, 'territorial'." (HAESBAERT, 2004, p. 20). Este contexto territorial nos remete de imediato à ideia de delimitação - por meio das relações dos indivíduos em uma determinada porção do espaço - bem como à noção de poder atrelado aos agentes e às ações que moldam o território, como já observado anteriormente. Sendo assim, partindo da concepção relacional, o território pode ser compreendido como lugar de todas as relações, cena do poder, campo de ação, ou seja, é uma produção. Portanto, "toda prática espacial (...) induzida por um sistema de ações ou de comportamentos se traduz por uma 'produção territorial' que faz intervir tessitura, nó e rede" (RAFFESTIN, 1993, p. 150).

\footnotetext{
${ }^{4}$ Ao referir-se à violência, busca-se a expansão da esfera física, visando abarcar algo maior, que está envolto de um poder real ou de uma ameaça resultante em deficiência ou privação, pois a violência também está ligada à calma, em saber utilizar técnicas de opressão discretas e requintadas.

${ }^{5}$ Ao usar o termo "não ausência do Estado" referimo-nos a um Estado ciente das necessidades e das demandas às quais determinados locais estão expostos, porém o mesmo se abstém de suprir tais demandas.
} 
Diante disso, o território carrega não só a construção material, mas também uma dimensão simbólico-identitária. Este é, simultaneamente, produto e meio de produção, conferindo a si a possibilidade de ser territorializado. Por sua vez, "a territorialidade é definida como um fenômeno de comportamento associado à organização do espaço em esferas de influência ou em territórios nitidamente diferenciados, considerados distintos e exclusivos (...) por seus ocupantes ou pelos que os definem" (RAFFESTIN, 1993, p. 159). Associado à presente análise, o movimento de territorialização se faz presente nas estratificações sociais - de um lado, os estratos privilegiados; de outro, os estratos subordinados à lógica da reprodução urbana.

Dialeticamente, essa territorialização se dá pela produção de espaços de exclusão/inclusão. Isso pode ser exemplificado dentro do que foi discutido anteriormente a respeito da espacialização da pobreza, onde temos a exclusão daqueles que se encontram marginalizados pelas condições socioeconômicas em que vivem, jogados nos amontoados periféricos das cidades por aqueles que detêm o direito de ocupá-la por meio do poder aquisitivo que possuem. Mas, ao mesmo tempo, essa fratura no espaço citadino forma parcelas espaciais homogêneas, nas quais determinados grupos sociais sentem-se incluídos pela condição semelhante em que se encontram - é o que Soja (2001) considera como um dos elementos da territorialidade, o senso de identidade espacial. Em contrapartida, tal fato é percebido como a desterritorialização "a partir dos grupos subordinados ou precariamente incluídos na dinâmica globalizadora" (HAESBAERT, 2004, p. 22).

Neste contexto, a territorialização da violência é paralela à dos agentes modeladores inseridos insatisfatoriamente na sociedade, o que por vezes se torna o seu catalisador. Contudo, é preciso compreender as facetas da violência enquanto fenômeno que se manifesta nas escalas espaciais e sociais.

Por sua vez, a violência é intrínseca ao homem e ao longo de toda a história tem-se manifestado no cotidiano citadino. De forma mais ampla, entende-se por violência uma situação em que um ou vários indivíduos agem de maneira direta ou indireta, causando danos a uma ou várias pessoas em níveis variados, seja em integridade física, moral, em suas posses, ou em suas participações simbólicas e culturais (MICHAUD, 1989, p. 11). Notadamente, a violência, afetando direta ou indiretamente os indivíduos, por consequência altera também seu cotidiano, suas práticas e relações, bem como aquela determinada organização espacial à qual estão inseridos.

Assim sendo, a vida social é constituída por interações sociais sempre heterogêneas e com constante potencial de conflitos e antagonismos. Logo, a violência urbana não poderia deixar de estar atrelada ao medo e às suas formas e manifestações diferenciadas, pois "o medo é um sentimento conhecido de toda criatura viva" (BAUMAN, 2007, p. 7). Podemos, portanto, definir medo como: "perturbação do ânimo preocupado com a ideia de um perigo real ou aparente. Temor, apreensão, receio" (RIOS, 2009, p. 345). 
A violência tem seu estopim com necessidades e interesses antropogênicos. Vale salientar que, na atualidade, esse fenômeno atingiu limites estratosféricos, podendo ser visto com mais incidência nos grandes centros urbanos. Segundo Morais (1995), a maioria dos crimes é resultante da opressão, das injustiças sociais, da miséria financeira ou afetiva. Quanto a isso, pode-se também atentar-se para a inserção da violência no cenário urbano, passível de explicação por meio das transformações às quais essa dimensão da vida humana está submetida:

As configurações que norteiam a violência vêm se transformando, seguindo muito mais uma tendência de reações a situações diversas. (...) A violência dita urbana é proveniente do convívio urbano, das relações deterioradas, da exclusão social, de toda uma dinâmica que se desenrola em um espaço único (...). A questão da violência perpassa principalmente pela questão social, de desigualdade há tempos marcada na sociedade brasileira que se desenvolveu de forma desarmônica, onde pequena parcela da população detém riquezas, enquanto que grande parte vive em situações bem inferiores, em meio, na maioria das vezes, a uma extrema pobreza. 0 espaço então se divide, denotando uma espacialização socioeconômica notória (DANTAS, 2005, p. 16).

A violência em ambiente urbano tecido pelo medo vem afetando cada vez mais a organização espacial das cidades. Os medos são variados e atrelados à realidade da qual se faz parte. "A violência urbana tem ampliado o que denominamos medo social. Medo esse construído socialmente e que afeta a coletividade" (BAIERL, 2004, p. 20). Isso vem causando cada vez mais isolamento e individualismo do ser humano devido à crescente sensação de insegurança que se instaura nos grandes centros urbanos. Nestes espaços é muito comum a aglomeração de pessoas que, em meio ao seu cotidiano, estão sempre em movimento. Temos a impressão de ver milhares de rostos e expressões e ao mesmo tempo não conseguimos ver ninguém.

Tudo o que se consegue distinguir são grupos que têm medo e o demonstram; e grupos que têm medo e não o demonstram. Sendo assim, o medo se torna mais presente no cotidiano da cidade. $\mathrm{Ou}$ seja, morar em grandes centros urbanos tem se tornado um ato de bravura e coragem, pois não se consegue mais enxergar o espaço amigo idealizado por Péricles na Grécia antiga. Segundo Morais (1995, p. 11), "em nenhum outro lugar a vida está sendo um jogo tão perigoso como nas grandes cidades".

De acordo com Tuan (2005, p. 231), “a cidade representa a maior aspiração da humanidade em relação à ordem perfeita e harmônica, tanto em sua estrutura arquitetônica como nos laços sociais". Mas no decorrer do tempo "a cidade tem sido oprimida pela violência e pela ameaça constante do caos" (Ibid., p. 251). Os grandes centros urbanos se tornaram o centro da especialização: todos os habitantes são obrigados a competir e se especializar ou sucumbirão ao meio em que estão inseridos; o que nos remete a Robert Auzelle, que fala do consumismo e suas implicações na cidade, já que o consumo faz as cidades e o excesso de consumo as desfaz.

Em meio ao ambiente capitalista, há aquelas pessoas que não conseguem acompanhar o ritmo de consumo diante do que é idealizado como uma necessidade imanente de consumir, o desejo de 
possuir objetos, e a partir do momento em que esses desejos não são saciados instala-se a frustração. Há aquelas outras que não podem consumir, mas que ao longo da vida obtêm a possibilidade de se inserir nesse sistema. Porém, têm ainda aquelas que não têm a possibilidade de consumir e a partir daí se frustram e se rebelam contra o sistema com agressividade.

0 fato é que se vive, em geral, amedrontados por muitas razões e nem todas estão ligadas ao crime. 0 medo apresenta muitas nuances. Tuan fala do medo da criança em seu crescimento, do desconhecido, de catástrofes naturais, da doença, da natureza etc. Vive-se constantemente ameaçados, seja pelo medo de sermos assaltados, o medo da polícia que circula entre a multidão portando armas de fogo que podem ser disparadas a qualquer momento ${ }^{6}$.

De um modo geral, onde há medo, há a iminência da ameaça; e onde se encontra a ameaça, se instaura a violência. 0 medo nada mais é que um fenômeno que é refletido na existência, no concreto. Ao ser tratado como tal, ele se materializa por meio de um sistema de ações e objetos que se consolida no espaço fomentando os territórios de violência em um contexto ambiental de medo.

\section{NOSSA SENHORA DA APRESENTAÇÃO: ANÁLISE DA CONSTITUIÇÃO DO TERRITÓRIO DA VIOLÊNCIA EM UM AMBIENTE DE MEDO}

A tessitura do espaço urbano do bairro Nossa Senhora da Apresentação antecede à constituição do que se considera aqui como territórios da violência em ambiente de medo, visto que é preciso levar em consideração o panorama em que o bairro surgiu, compreendendo que ele carrega em sua construção diversos contrastes sociais, econômicos e estruturais.

De acordo com Barbosa (2007), a Zona Norte em si surgiu em função do padrão de renda da população migrante, sendo predominantemente construída pela Companhia Habitacional, que abrangeu 83\% das construções na área, atendendo uma população de menor faixa de renda. Dentre os problemas locais, destacam-se os seguintes: ausência de infraestrutura e serviços básicos, um dos traços expressivos na paisagem urbana brasileira, práticas atreladas à defasagem da qualidade de vida dos moradores como a violência levando-nos a concluir que sua raiz se vincula à problemática da desigualdade social.

Nesse cenário de violência em ambiente de medo que se propaga pela cidade de Natal, destaca-se, portanto, o bairro Nossa Senhora da Apresentação, situado na Zona Norte da cidade, que apresenta altos índices de Crime de Violência Letal Intencional (CVLI), sendo o primeiro bairro com maior incidência nesta categoria de criminalidade e violência no município.

\footnotetext{
${ }^{6}$ Recentemente, ocorreu o caso em que uma família no Rio de Janeiro se dirigia para um chá de bebê e seu carro foi alvejado por mais de 80 tiros de fuzil. São fatos como esse que ganham grande repercussão e expandem as fronteiras do medo, tendo em vista que tal ocorrência pode acontecer com qualquer pessoa.
} 
Segundo o documento "Natal: Conheça melhor seu bairro-2012", elaborado pela Secretaria de Meio ambiente e Urbanismo (SEMURB), o nome do bairro é uma homenagem à Padroeira de Natal. Foi fundado na década de 1990, na gestão do Prefeito Aldo Tinoco (1993-1996), como uma unidade territorial planejada, e em 05 de abril de 1993 teve suas fronteiras legais definidas pela lei 4.328/93. Porém, o período de ocupação de suas terras teve início em 1970 e, em 1980, a Caixa Econômica Federal financiou a construção do primeiro conjunto habitacional do bairro: o Conjunto Parque dos Coqueiros. Além de outros conjuntos habitacionais construídos posteriormente, o bairro também é constituído por loteamentos e áreas de assentamentos populares.

\begin{abstract}
O Bairro Nossa Senhora da Apresentação surgiu na década de 1970, atrelado às políticas habitacionais empreendidas durante o Regime Militar Brasileiro (19641985), que por sua vez foram financiadas via instituições públicas de provimento da casa própria, como a Companhia da Habitação (COHAB), subordinada ao Banco Nacional de Habitação (BNH). O Nossa Senhora da Apresentação é considerado um bairro periférico, situado na região administrativa Norte da cidade, onde possui consideráveis extensões territoriais e demográficas (...) (SILVA, 2012, p. 1).
\end{abstract}

Portanto, o bairro conta com uma extensão de 1.024,79 hectares, caracterizando-se como o segundo maior bairro de $\mathrm{Natal}^{7}$ e o mais populoso, contando com 79.759 residentes, que apresentam renda entre $1 / 4$ e 1 salário mínimo segundo o IBGE (2010). Nossa Senhora da Apresentação se caracteriza como um lugar de transição entre Natal e sua Região Metropolitana, limitando-se ao norte com o bairro Lagoa Azul e o município de São Gonçalo do Amarante; ao sul com Igapó e o município de São Gonçalo do Amarante; a oeste com o município de São Gonçalo do Amarante e a leste com os bairros Lagoa Azul e Potengi.

A territorialização do bairro no município corrobora a constituição de mais um espaço de desigualdades socioeconômicas, pois suas fronteiras se tornam enclaves que segregam a riqueza dos parques industriais e a pobreza dos conjuntos habitacionais. Desde sua ocupação ocorreu a consolidação como uma área de concentração de população em comparação aos outros bairros onde, de acordo com Silva (2013), em meados da década de 1970, ocorreu um grande fluxo migratório com a criação dos loteamentos Vale Dourado, Boa Sorte, Aliança, Bom Jesus, Santarém, Libanês e Jardim Progresso (Figura 1).

${ }^{7} 0$ primeiro é o bairro Lagoa Azul. 
Figura 1. Delimitação dos Loteamentos do bairro Nossa Senhora da Apresentação em Natal/RN.

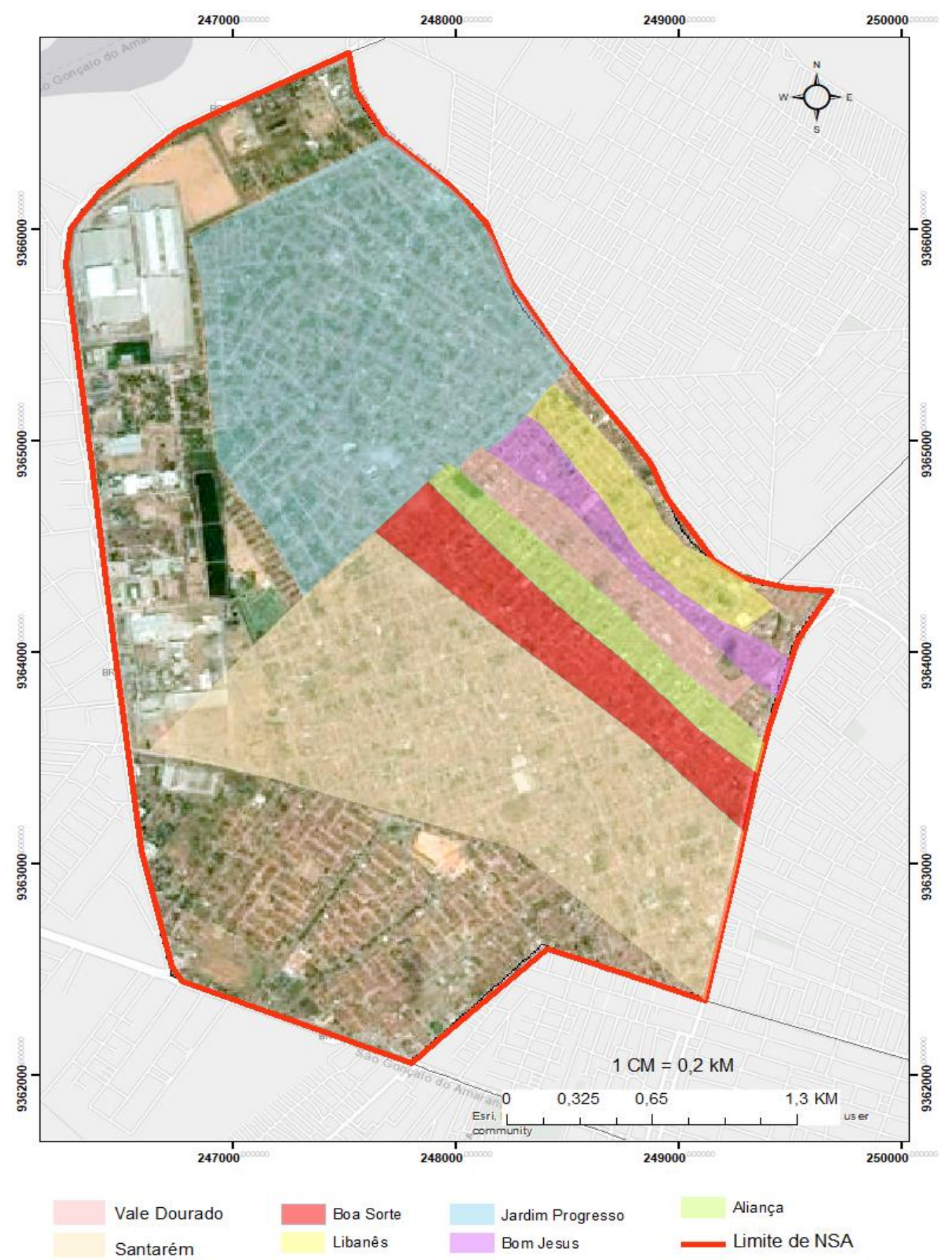

Fonte: Google Earth, 2013. Adaptado pelos autores.

O bairro Nossa Senhora da Apresentação detém altos índices de desigualdades socioespaciais, acentuando o fomento de territórios da violência, visto que no referido bairro a pobreza encontra-se enraizada desde o início de sua ocupação agindo como modeladora deste território. 0 atual cenário urbano é extremamente complexo e tende a ampliar tais desigualdades na medida em que se encontra cada vez mais marcado pelo aumento dos índices de violência e criminalidade reforçando o atual ambiente de medo. 
Em Natal, a escalada da violência, de forma geral, tem sido um fenômeno cada vez mais notório não só pela sensação de insegurança que se instaura no cotidiano da população, mas também pelos dados que o comprovam. Natal é uma grande cidade de região "subdesenvolvida" e como tal não está isenta do fenômeno da criminalização, tendo em vista que em uma década deixou de ser uma capital tranquila: em 2002 apresentou índices de 102 assassinatos, enquanto que, em 2012 este índice chegou a 456. Teve-se, assim, um crescimento significativo, registrando em curto período uma elevação do índice de CVLI em torno de 347,1\%. A figura 2 evidencia uma significativa espacialização deste índice em Natal.

Figura 2. Espacialização dos CVLI no 1os semestre de 2018 nas Zonas Administrativas de Natal/RN.

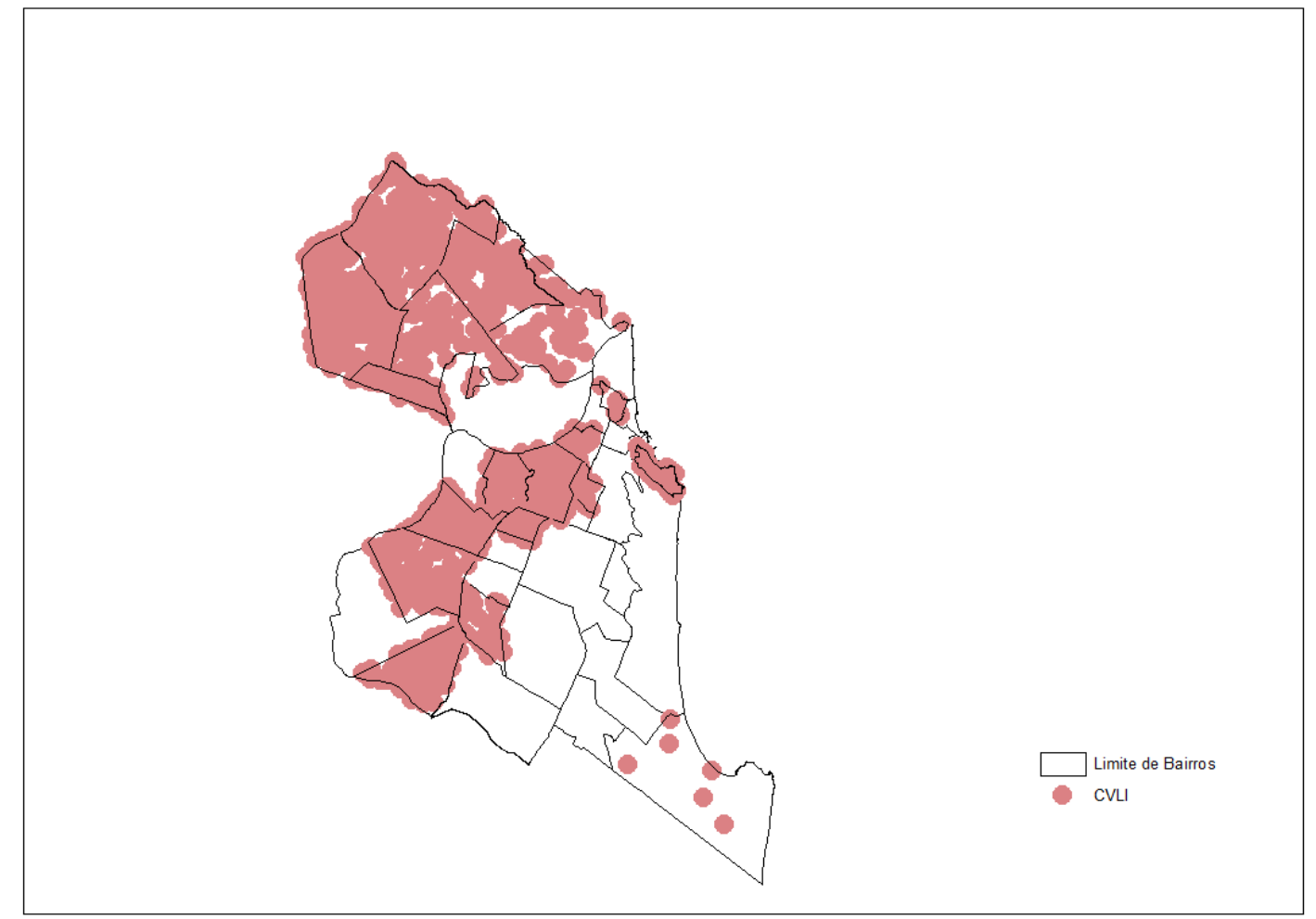

Fonte: Observatório da Violência do Rio Grande do Norte (OBVIO), 2019.

É possível verificar que as taxas de CVLI são maiores nas Zonas Administrativas Norte e Oeste. Nessas áreas há uma concentração de assentamentos populares - denominado pelo IBGE de "aglomerados subnormais"8 - onde a população predominantemente de baixa renda se instala sem um planejamento prévio. 0 que evidencia a não ausência do Estado, pois o mesmo sabe das necessidades e

\footnotetext{
${ }^{8}$ Aglomerados subnormais são unidades habitacionais caracterizadas por ausência de título de propriedade, irregularidade das vias de circulação, do tamanho e forma dos lotes e/ou carência de serviços públicos essenciais (como coleta de lixo, rede de esgoto, rede de água, energia elétrica e iluminação pública). Sua existência está relacionada à forte especulação imobiliária e fundiária e ao decorrente espraiamento territorial do tecido urbano, à carência de infraestruturas as mais diversas, incluindo de transporte e, por fim, à periferização da população. Surgem, nesse contexto, como uma resposta de uma parcela da população à necessidade de moradia, e que irá habitar espaços menos valorizados pelo setor imobiliário e fundiário dispersos pelo tecido urbano (IBGE, 2010).
} 
dos anseios dos moradores locais, porém se faz insuficiente em suprir suas demandas. E como não existe vazio de poder, o Estado, ao deixar lacunas, dá margem para outros agentes territorializarem-se para exercerem poder sobre essas áreas.

Segundo os dados coletados no OBVIO, em 2018, Nossa Senhora da Apresentação é o bairro mais violento da cidade de Natal; no primeiro semestre de 2015 apresentou 27 assassinatos, enquanto que no mesmo período de 2016 foram registrados 28 homicídios, o que representa um aumento de 4\%. Em 2017 ocorreu o registro de 34 CVLI na área, enquanto que em 2018 houve 31 homicídios no mesmo período, o que representa um decréscimo de 9\% no índice de Violência Letal Intencional, mas ainda assim não deixa de ser um percentual relevante no que diz respeito à disseminação da violência nesta localidade.

Como expresso através dos dados, Nossa Senhora da Apresentação caracteriza-se como um território de violência em meio ao ambiente de medo que se vem tecendo nas áreas urbanas brasileiras. Esse território carrega consigo as marcas de um tipo problemático de organização espacial e de uma alta densidade demográfica (de 77,83 hab/há), que caracteriza o bairro como populoso e com baixos Índices de Desenvolvimento Humano (IDH): das 79.759 pessoas que habitam esse bairro, 77\% vivem com menos de um salário mínimo por mês, de acordo com a SEMURB.

No tocante à infraestrutura, o quadro é ainda mais alarmante, pois segundo o IBGE (2010), dos logradouros existentes, $54 \%$ não se encontravam identificados e apenas $27 \%$ das casas tinham calçadas, sem mencionar a pavimentação a qual não cobre toda a extensão do bairro dificultando a garantia do direito básico de ir e vir dos moradores.

Diante desse quadro de referências, as principais demandas das populações locais traduzemse, principalmente, na melhoria em termos de drenagem, esgotamento sanitário, saúde e segurança pública; tratando-se estas de condições fundamentais à conquista do direito à cidade, as quais, aliás, têm que ser garantidas pelo poder público numa perspectiva efetivamente inclusiva.

Acredita-se, então, que, uma vez atendidas as demandas acima mencionadas, promovendo, efetivamente, a garantia das condições para a construção do que Santos (1987) definiu como espaço do cidadão, rumo ao direito à cidade, ter-se-ão os parâmetros fundamentais para à reversão do atual quadro de violência nas cidades e, por conseguinte, o ambiente de medo que vem, em certa medida, fragmentando ainda mais a sociedade brasileira.

\section{CONSIDERAÇÕES FINAIS}

Estudos sobre um tema tão delicado como os territórios de violência em ambiente de medo nas cidades têm-se mostrado fundamentais, pois a partir de análises de territórios como o do bairro Nossa Senhora da Apresentação, é possível compreender as novas dinâmicas territoriais, o que se faz 
de extrema importância. Isto devido à atual estrutura da sociedade, que se encontra pautada nas desigualdades sociais e corrobora com o aumento das mazelas sociais que atingem a população.

A violência e o ambiente de medo são agentes espaciais, que são determinantes e determinados de acordo com a organização dos sujeitos que vivem e se estabelecem sob os parâmetros do que é dito "seguro". Esses movimentos ajudam na fomentação de territórios regidos pelo medo do crime, que vão erguer novas barreiras a partir da taxação do inseguro.

0 medo passou a controlar a vida dos habitantes das grandes cidades, que se enclausuram na busca desesperada por proteção. O conto "Segurança" de Luís Fernando Veríssimo retrata essa busca vertiginosa por segurança, onde a tecnosfera se insere no cotidiano de tal forma que as pessoas passam a viver em verdadeiras prisões. Morar em centros urbanos passou a ser um ato de resistência onde, na busca de se resguardar, os cidadãos passaram a mudar seus hábitos como, por exemplo, o simplório hábito de sentarem-se nas calçadas e conversarem com vizinhos.

Ademais, a despeito de não ter sido considerada na análise que se acabou de fazer neste texto, existe ainda uma preocupação a ser objeto talvez de outra reflexão, isto é, em que medida, por detrás do atual ambiente de medo que se tece e se propaga nas cidades, não há a intencionalidade de afastar as pessoas dos espaços públicos, fragmentando ainda mais a sociedade brasileira.

Ao mesmo tempo, não se deve negligenciar, no atual processo de territorialização do urbano, o peso da cooptação do referido ambiente pelos interesses capitalistas, na medida em que há setores econômicos que estão ganhando muito dinheiro vendendo pacotes de sistemas técnico-científicosinformacionais de segurança, bem como oferecendo serviços de arregimentação de vigilantes para condomínios residenciais e empresariais.

Pleitear sobre tal temática se faz de extrema importância, porque inúmeras questões sobre o território da violência e do medo precisam ser respondidas. Assim, também a geografia se faz um dispositivo importantíssimo na conexão e compreensão da realidade do espaço, sendo este um componente fundamental para o planejamento urbano e do Estado para a elaboração de projetos e políticas públicas.

\section{REFERÊNCIAS}

BAIERL, Luzia Fátima. Medo social: da violência visível ao invisível da violência. [S.l.]: Cortez, 2004. 204 p.

BARBOSA, Ana Cristina. Produção socioespacial da comunidade Boa Sorte/Aliança (Zona Norte de Natal). Natal/RN: [s. n.], 2007.

BAUMAN, Zygmunt. Medo Líquido. [S.l.]: ZAHAR, 2008. 239 P.

BAYER, Hiram de Aquino; DANTAS, Eugênia Maria. Notas teóricas. Notas teóricas para o estudo do medo pela Geografia, Cofins, n. 36, p. 1-10, 16 mar. 2018.

BAYER, Hiram. Pelos caminhos de um labirinto: reflexões sobre as territorializações do medo no bairro de Candelária, Natal-RN. 2010. Tese (Mestrado em Geografia) - UFRN, [S. 1.], 2016. Disponível em: http://repositorio.ufrn.br/handle/123456789/21 306. Acesso em: 11 fev. 2019 
CARVALHO, José Jorge de. As tecnologias de segurança e a expansão metonímica da violência. Série Antropologia, Brasília, 2000.

CORREAA, Roberto Lobato. O espaço Urbano. São Paulo: Editora Ática S.A., 1989.

DANTAS, Camila. Territórios da violência: um estudo acerca da criminalidade na Zona Norte de Natal/RN. Natal/RN, [s. n.], 2005.

FOUCAULT, M. A ordem do Discurso: aula inaugural no Collége de France, pronunciada em 2 de dezembro de 1970. São Paulo: Edições Loyola, 1996.

FOUCAULT, M. Vigiar e punir: nascer da prisão. Petrópolis, RJ: Vozes, 2013. 41. ed.

GODINHO, Isabel Cavalcante. Pobreza e desigualdade social no Brasil: um desafio para as Políticas Sociais. Ipea, [S. l.], 2011. Disponível em: http://www.ipea.gov.br/code2011/chamada2011 /pdf/area2/area2-artigo31.pdf. Acesso em: 28 maio 2019.

HAESBAERT, Rogério. $O$ Mito da Desterritorialização: Do "fim dos territórios" à multiterritorialidade. Rio de Janeiro: Bertrand Brasil, 2004.

IBGE. CENSO 2010: aglomerados subnormais informações territoriais. [S. 1.: s. n.], 2010. Disponível em: https://ww2.ibge.gov.br/home/presidencia/notic ias/imprensa/ppts/00000015164811202013480 105748802.pdf. Acesso em: 31 maio 2019.

IVENIO HERMES. OBVIO - Observatório da Violência Letal Intencional no RN. [S. 1.], 2018. Disponível em: http://www.iveniohermes.com/boletinsobvio/. Acesso em: 15 abr. 2019.

MELARA, Eliane. A dinâmica da violência criminal no espaço urbano de Santa Maria - RS. [S.l.: s.n.], 2008. $182 \mathrm{p}$.

MELGAÇO, Lucas. Securitização Urbana: da psicoesfera do medo e á tecnosfera da segurança. 2009. 274 p. Dissertação (Doutorado em Geografia) - USP, [S.l.], 2010.

MINAYO, Maria Cecília. Conceitos, teorias e tipologias de violência: a violência faz mal à saúde. [S. l.], 2007. Disponível em: http://www1.londrina.pr.gov.br/dados/images/s tories/Storage/sec_mulher/capacitacao_rede $\% 20$ /modulo_2/205631conceitos_teorias_tipologias_violencia.pdf. Acesso em: 22 mar. 2019.

MONTEIRO, Carlos Augusto. A dimensão da pobreza, da desnutrição e da fome no Brasil. Estudos Avançados. São Paulo, v. 17, n. 48, p. 7-20, 2003. Disponível em: <http://www.scielo.br/scielo.php?script=sci_artte xt\&pid=S0103 40142003000200002\&lng=en\&nrm=iso >. Acesso em: 28 maio 2019.
MORAIS, Regis. O que é violência Urbana. São Paulo: Editora Brasiliense, 1995.

ODALIA, Nilo. O que é violência. São Paulo: Editora Brasiliense, 1985.

RAFFESTIN, Claude. Por uma Geografia do poder. São Paulo: Editora Ática S.A., 1993.

SANTOS, Luciana 0. O Medo Contemporâneo: Abordando suas diferentes concepções. [S.l.: s.n.], 2003.

SANTOS, Milton. O espaço do cidadão. São Paulo: Nobel, 1987.

SANTOS, Milton et al. O Papel Ativo da Geografia: um manifesto. XII Encontro Nacional de Geógrafos. Florianópolis, jul. 2000. 15 p. Também disponível em: <http://www.ub.es/geocrit/b3w-270.htm>. Acesso em: 20.maio.2019

SANTOS, Milton; SILVEIRA, Maria Laura. O Brasil: território e sociedade no início do século XXI. Rio de Janeiro: Record, 2001. 473 p.

SEMURB. Conheça melhor seu bairro. In: SEMURB. Nossa Senhora da Apresentação. [S. l.: s. n.], 2012. Disponível em: www.natal.rn.gov.br/semurb. Acesso em: 28 maio 2019.

SILVA E SILVA, Maria Ozanira. Pobreza, desigualdade e políticas públicas: caracterizando e problematizando a realidade brasileira. Katál, Florianópolis, 30 maio 2019.

TUAN, Yi-fu. Paisagens do Medo. São Paulo: Editora UNESP, 2005. 374 p. 